\title{
Determination of blast resistance of selected structural elements
}

\author{
Matúš Ivančo ${ }^{1, *}$, Jovan Trajkovski ${ }^{2}$, Lucia $_{\text {Figuli }}{ }^{1}$ and Romana Erdélyiová ${ }^{1}$ \\ ${ }^{1}$ University of Žilina, Faculty of Security Engineering, Univerzitná 8215/1, 01026 Žilina, Slovak \\ Republic \\ ${ }^{2}$ University of Ljubljana, Department of Modelling in Engineering Sciences and Medicine, Ljubljana, \\ Slovenia
}

\begin{abstract}
At the present time of political and war conflicts between countries, more and more attention is focused on the protection of important structures, being part of critical infrastructure, such as buildings of energy importance, government buildings or military bases. Regardless of the type of industry area, primarily, buildings needed to be protected. For this reason, the paper is focused on the determination of resistance of selected structural elements creating the protection system against the effects of the blast from the explosion, including terrorist attack. The paper has need of analysing the behaviour of structural elements affected by the blast load and setting the structural resistance of elements loaded by such dynamic type of load. The outputs can serve as a basis for the design of an effective plan for the protection of a selected elements of critical infrastructure, which ultimately represents not only the protection of the buildings themselves, but also the affected people presented inside the buildings.
\end{abstract}

\section{Introduction}

To assess the resistance of structure to high pressure, several factors that affect the magnitude of the consequences of the explosion have to be considered. These factors include the weight of the charge, the distance between the building and the place of the explosion (so called stand-off distance), the type of explosive and the type of building material. Obviously, many other factors affect the effects of the explosion, which are discussed in more detail in the following sections. However, it is necessary to mention that these consequences can be prevented by early detection of an intruder on the premises and rapid intervention by the security service or police [1].

To determinate the blast resistance of the structure is not simply task. Primarily blast wave propagation has to be described and the maximal pressure has to be set, more research in [2], consequently dynamical analysis of the structure has to be made, modal analysis [3, 4], spectral analysis [5] to obtain the structural response of blast loaded structure [6]. Various blast test were conducted [7, 8] to determine blast resistance [9-11].

\footnotetext{
* Corresponding author: matus.ivanco@ fbi.uniza.sk
} 


\section{Analytical approach}

The response of the structural element based on the model is determined in the analytical approach. The real structure is replaced by a simplified model. The mass of the element is concentrated into individual points. The response of the simplified mechanical system loaded by pressure is calculated. Among such analytical models, we include the Single Degree of Freedom model (SDOF).

\subsection{SDOF (Single Degree of Freedom)}

For SDOF models, we consider the minimum number of coordinates needed to fully determine the position of all parts of the system at any time, which define the degree of freedom of the system. A system with single degree of freedom is characterized by the fact that at any given moment its position can be defined by only one coordinate. For elements under impulsive load (blast load), damping is much less important, because maximum response is achieved in a very short time before the damping forces can absorb most of the energy from the structure [12].

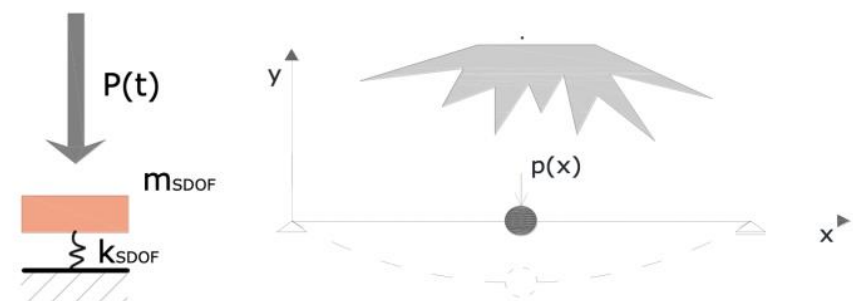

Fig. 1. SDOF model of blast loaded structure [12].

\subsection{Blast load}

In the first step, blast load has to be determined. The average values based on empirical formulas and probable values of the factors are taken into account in the analytical approach. This concept ultimately influences the accuracy of the results. Estimations of peak overpressure due to spherical blast are based on scaled distance $Z$ according to (1)

$$
Z=\frac{R}{W^{\frac{1}{3}}}
$$

where $R$ real distance from explosion to the structure in meters and $W$ is charge weight in kilograms [13]. Various empirical formulas were developed, described in [14] as well as the relationship (2) with adequate accordance with the conducted tests

$$
P_{+}=\left(\frac{0.202}{Z}+\frac{0.224}{z^{2}}+\frac{1.182}{z^{3}}\right) \cdot 0.5 \cdot e^{0.035 R}
$$

where $P_{+}$represents overpressure in the reflected wave [MPa] 


\subsection{Structural response}

Assessing the safety of structure, it is necessary to take into account the load-bearing limit $R_{t f d .}$ Exceeded it leads to cracks in the materials [15]. The following condition must be applied

$$
\min \left(\sigma_{g} \pm \sigma_{\text {expl }}\right) \geq-R_{t f d} \text { which implies } \sigma_{\text {expl }}-\sigma_{g} \leq R_{t f d}
$$

where $\sigma_{\text {expl }}$ represents the stress generated by the blast wave and $\sigma_{g}$ the normal stress at a particular point in the structure.

An important factor is also the value of the permissible limit rotation $\Psi$. In the case of structural failure is between $2.3^{\circ}-5.7^{\circ}$ in the case of masonry structures, $6.5^{\circ}$ in the case of reinforced concrete and $10.5^{\circ}$ in the case of steel structures. The rotation is determined by the relation:

$$
\psi=2 \operatorname{arctg}\left(2 \cdot \frac{y}{l}\right)
$$

where $y$ represents the maximum achieved deflection of the wall and $l$ the span of the structure (in its shorter direction). In order to facilitate the calculation, uniform linear load of the structure from the blast wave were assumed. On this basis, the structural response derived from the equivalent static load $p_{e k v}$, can be easily determined using the dynamic factor $\delta$, the overpressure of the wave $p_{\text {ref }}$ is determined.

$$
p_{e k v}=\delta \cdot p_{\text {ref }}
$$

The calculation of bending moments for rectangular plate shapes is based on the following formulas if the Poisson constant $\mu=0$ :

$$
\begin{gathered}
\max m_{x}=\alpha_{x} \cdot q \cdot l_{x}^{2} \\
\max m_{y}=\alpha_{y} \cdot q l_{y}^{2} \\
\min m_{x v s}=\alpha_{x v s} \cdot q \cdot l_{x}^{2} \\
\min m_{y v s}=\alpha_{y v s} \cdot q \cdot l_{y}^{2} \\
\max m_{x y}=\max m_{y x}=\alpha_{x y} \cdot q \cdot l_{y}^{2} \\
w_{s}=\beta \cdot \frac{q \cdot l_{x}^{4}}{E \cdot h^{3}}
\end{gathered}
$$

where max $m_{x}$ and $\max m_{y}$ represents the maximum bending moment per unit of length perpendicular to $x / y, m_{x v s}$ and $m_{y v s}$ support moments per unit of length perpendicular to $x / y$, $\max m_{x y}$ and max $m_{y x}$ extreme torque per a unit of side length perpendicular to $x / y$ and $w_{s}$ as the vertical deflection of the center of the plate.

If the Poisson constant $\mu \neq 0$, the approximate values of the bending moments $m_{x \mu}$ and $m_{y \mu}$ can be obtained from the bending moments $m_{x 0}$ and $m_{y 0}$, based on the following formulas

$$
m_{x \mu}=m_{x 0}+\mu m_{y 0}
$$




$$
m_{y \mu}=\mu m_{x 0}+m_{y 0}
$$

The torque moment and deflection are calculated as follows

$$
\begin{gathered}
m_{x y \mu}=(1-\mu) \cdot m_{x y 0} \\
w_{\mu}=\left(1-\mu^{2}\right) \cdot w_{0}
\end{gathered}
$$

For the possibility of subsequent comparison of the results of analytical calculations, we took the values of uniform blast load from the measured experiments [16], which were carried out on a masonry wall of size $2200 \times 2575 \times 65 \mathrm{~mm}$, mounted in a steel frame from cylindrical U profiles. Values of basic input quantities were determined as follows:

- $\quad$ ductility coefficient for masonry $k_{m}=2.1$,

- modulus of elasticity of material $E=473 \mathrm{MPa}$,

- material unit weight $\gamma=1800 \mathrm{~kg} / \mathrm{m}^{3}$,

- $\quad$ overpressure time $=0.3 \mathrm{~s}$,

\begin{tabular}{|c|c|c|c|c|c|c|c|c|c|c|}
\hline $\begin{array}{c}p_{\max } \\
{[\mathrm{kPa}]}\end{array}$ & $h[\mathrm{~m}]$ & $\lambda^{2}[-]$ & $\delta[-]$ & $\begin{array}{c}m_{x} \\
{[\mathbf{k N m}]}\end{array}$ & $\begin{array}{c}m_{y} \\
{[\mathbf{k N m}]}\end{array}$ & $\begin{array}{c}m_{x v s} \\
{[\mathbf{k N m}]}\end{array}$ & $\begin{array}{c}m_{y v} s \\
{[\mathrm{kNm}]}\end{array}$ & $\begin{array}{c}w_{s} \\
{[\mathbf{m m}]}\end{array}$ & $\begin{array}{c}\Psi \\
{[\mathrm{deg}]}\end{array}$ & $\begin{array}{c}\boldsymbol{\Psi}^{*} \\
{[\%]}\end{array}$ \\
\hline 6.23 & \multirow{6}{*}{0.065} & 31.56 & 0.966 & 0.78 & 0.56 & -1.83 & -1.61 & 21.22 & 2.21 & 73.67 \\
\hline 2.09 & & 31.56 & 0.966 & 0.26 & 0.19 & -0.61 & -0.54 & 7.12 & 0.74 & 24.67 \\
\hline 2.41 & & 31.56 & 0.966 & 0.30 & 0.22 & -0.71 & -0.62 & 8.21 & 0.86 & 28.67 \\
\hline 6.76 & & 31.56 & 0.966 & 0.85 & 0.61 & -1.98 & -1.75 & 23.03 & 2.40 & 80.00 \\
\hline 6.72 & & 31.56 & 0.966 & 0.84 & 0.61 & -1.97 & -1.74 & 22.89 & 2.38 & 79.33 \\
\hline 5.79 & & 31.56 & 0.966 & 0.72 & 0.52 & -1.70 & 1.50 & 19.73 & 2.05 & 68.33 \\
\hline
\end{tabular}

- Poisson's coefficient $v=0.15$.

Table 1. Determination of pressure effect on masonry wall thickness $65 \mathrm{~mm}$.

Subsequently, we also calculated the values for the wall construction thicknesses determined on the basis of the National Security Authority's Methodological Guidelines of Slovak republic, requiring the wall thickness of $100 \mathrm{~mm}, 150 \mathrm{~mm}$ and $300 \mathrm{~mm}$ (see Table 2), where $p_{\max }$ - maximum overpressure, $h$ - wall thickness, $m_{x}$ - maximum bending moment perpendicular to the $x$ direction, $m_{y}$ - maximum bending moment perpendicular to the $y$ direction, $m_{x v s}$ - support moment perpendicular to $x$ direction, $m_{x v S}$ - support moment perpendicular to $y$ direction, $w_{s}$ - maximum deflection, $\Psi$ - rotate the centre of the wall and $\Psi^{*}$ - reaches the refractive angle in the middle of the wall. 
Table 2. Determination of pressure effect on masonry walls thickness $100 \mathrm{~mm}, 150 \mathrm{~mm}, 300 \mathrm{~mm}$.

\begin{tabular}{|c|c|c|c|c|c|c|c|c|c|c|}
\hline $\begin{array}{c}p_{\max } \\
{[\mathrm{kPa}]}\end{array}$ & $h[\mathbf{m}]$ & $\lambda^{2}[-]$ & $\delta[-]$ & $\begin{array}{c}m_{x} \\
{[\mathrm{kNm}]}\end{array}$ & $\begin{array}{c}m_{y} \\
{[\mathrm{kNm}]}\end{array}$ & $\begin{array}{c}m_{x v s} \\
{[\mathrm{kNm}]}\end{array}$ & $\begin{array}{c}m_{y y} s \\
{[\mathbf{k N m}]}\end{array}$ & $\begin{array}{c}w_{s} \\
{[\mathbf{m m}]}\end{array}$ & $\begin{array}{c}\Psi \\
{[\mathrm{deg}]}\end{array}$ & $\begin{array}{c}\Psi^{*} \\
{[\%]}\end{array}$ \\
\hline 6.23 & \multirow{6}{*}{0.1} & 31.56 & 1.107 & 0.89 & 0.64 & -2.09 & -1.85 & 6.68 & 0.70 & 23.33 \\
\hline 2.09 & & 31.56 & 1.107 & 0.30 & 0.22 & -0.70 & -0.62 & 2.24 & 0.23 & 7.67 \\
\hline 2.41 & & 31.56 & 1.107 & 0.35 & 0.25 & -0.81 & -0.71 & 2.58 & 0.27 & 9.00 \\
\hline 6.76 & & 31.56 & 1.107 & 0.97 & 0.70 & -2.27 & -2.00 & 7.25 & 0.75 & 25.00 \\
\hline 6.72 & & 31.56 & 1.107 & 0.96 & 0.70 & -2.26 & -1.99 & 7.20 & 0.75 & 25.00 \\
\hline 5.79 & & 31.56 & 1.107 & 0.83 & 0.60 & -1.95 & -1.72 & 6.21 & 0.65 & 21.67 \\
\hline 6.23 & \multirow{6}{*}{0.15} & 31.56 & 1.196 & 0.96 & 0.70 & -2.26 & 1.99 & 2.14 & 0.22 & 7.33 \\
\hline 2.09 & & 31.56 & 1.196 & 0.32 & 0.23 & -0.76 & -0.67 & 0.72 & 0.07 & 2.33 \\
\hline 2.41 & & 31.56 & 1.196 & 0.37 & 0.27 & -0.87 & -0.77 & 0.83 & 0.09 & 3.00 \\
\hline 6.76 & & 31.56 & 1.196 & 1.05 & 0.76 & -2.45 & -2.16 & 2.32 & 0.24 & 8.00 \\
\hline 6.72 & & 31.56 & 1.196 & 1.04 & 0.75 & -2.44 & -2.15 & 2.30 & 0.24 & 8.00 \\
\hline 5.79 & & 31.56 & 1.196 & 0.90 & 0.65 & -2.10 & -1.85 & 1.99 & 0.21 & 7.00 \\
\hline 6.23 & \multirow{6}{*}{0.30} & 31.56 & 1.271 & 1.02 & 0.74 & -2.40 & -2.12 & 0.28 & 0.03 & 1.00 \\
\hline 2.09 & & 31.56 & 1.271 & 0.34 & 0.25 & -0.81 & -0.71 & 0.10 & 0.01 & 0.33 \\
\hline 2.41 & & 31.56 & 1.271 & 0.40 & 0.29 & -0.93 & -0.82 & 0.11 & 0.01 & 0.33 \\
\hline 6.76 & & 31.56 & 1.271 & 1.11 & 0.80 & -2.61 & -2.30 & 0.31 & 0.03 & 1.00 \\
\hline 6.72 & & 31.56 & 1.271 & 1.11 & 0.80 & -2.59 & -2.29 & 0.31 & 0.03 & 1.00 \\
\hline 5.79 & & 31.56 & 1.271 & 0.95 & 0.69 & -2.23 & -1.97 & 0.26 & 0.03 & 1.00 \\
\hline
\end{tabular}

\section{Experimental testing}

Experimental testing of masonry structure was realized by Dr. Makovička, in cooperation with the Research Institute in Ostrava-Radvanice in their experimental tunnel in Štramberk. The tests were carried out on a masonry wall built of solid bricks (290x140x65 mm) with a strength designation P10, which was joined by class 4 lime-cement mortar (MVC4). 




Fig. 2. Time course of blast load of masonry wall [18].

The masonry partition $(2200 \times 2575 \times 65 \mathrm{~mm})$ was fixed in a steel frame consisting of cylindrical U profiles. A total of 7 tests were performed during which the applied pressure was changed. In the seventh test, a brick wall broke through. Therefore, it is possible to see in Fig. 2 a different course of the pressure function than in the other cases. The resulting measured values of the load and the reaction of the masonry wall to the effects of the explosion are shown in Table 3 [18].

Table 3. Results of blast load and response of masonry wall [18].

\begin{tabular}{|c|c|c|c|c|c|c|c|c|c|}
\hline $\mathbf{N}^{\circ}$ & $\begin{array}{c}p_{\max } \\
{[\mathrm{kPa}]}\end{array}$ & $\begin{array}{c}y_{\max } \\
{[\mathrm{mm}]}\end{array}$ & $\begin{array}{c}\boldsymbol{E}_{d e f} \\
{[\mathrm{MPa}]}\end{array}$ & $\begin{array}{c}\sigma_{c} \\
{[\mathrm{kPa}]}\end{array}$ & $\begin{array}{c}\sigma_{t} \\
{[\mathrm{kPa}]}\end{array}$ & $\begin{array}{c}\sigma_{s} \\
{[\mathrm{kPa}]}\end{array}$ & $\begin{array}{l}r_{t f d} \\
{[-]}\end{array}$ & $\begin{array}{c}\Psi \\
{[\mathrm{deg}]}\end{array}$ & $\begin{array}{c}\Psi^{*} \\
{[\%]}\end{array}$ \\
\hline 1 & \multicolumn{9}{|c|}{ not measured } \\
\hline 2 & 6.23 & \multicolumn{8}{|c|}{ not measured } \\
\hline 3 & 2.09 & 4.821 & 732 & 412 & 664 & 807 & 40 & 0.552 & 18 \\
\hline 4 & 2.41 & 6.506 & 629 & 475 & 765 & 930 & 46 & 0.746 & 25 \\
\hline 5 & 6.76 & 22.640 & 512 & 1333 & 2149 & 2611 & 131 & 2.594 & 86 \\
\hline 6 & 6.72 & 23.952 & 494 & 1324 & 2135 & 2594 & 130 & 2.744 & 91 \\
\hline 7 & 5.79 & \multicolumn{8}{|c|}{ total damage } \\
\hline
\end{tabular}

During the individual tests, the material gradually degraded and thereby lost its bending stiffness. This caused an overall weakening of the structure and a faster breakthrough in subsequent tests [19]. 


\section{Determination of blast resistance}

Studying the response of walls on the blast load is essential for the protection of people. It is important to determine blast resistance, i.e. ability of the structure to resist of the effect of blast from the explosion of explosive substances. After comparing the results of analytical calculations and real experiments, it was possible to calculate the pressure magnitudes for the individual wall thicknesses according to the methodical guideline, when the masonry walls is highly damaged. These results are only indicative, due to deviations resulting from expert estimates.

Table 4. Limited pressure values of blast resistance for different wall thicknesses.

\begin{tabular}{|c|c|c|c|c|c|c|c|c|c|c|}
\hline $\begin{array}{c}\boldsymbol{p}_{\max } \\
{[\mathbf{k P a}]}\end{array}$ & $\boldsymbol{h}[\mathbf{m}]$ & $\lambda^{2}[-]$ & $\boldsymbol{\delta}[-]$ & $\begin{array}{c}\boldsymbol{m}_{\boldsymbol{x}} \\
{[\mathbf{k N m}]}\end{array}$ & $\begin{array}{c}\boldsymbol{m}_{\boldsymbol{v}} \\
{[\mathbf{k N m}]}\end{array}$ & $\begin{array}{c}\boldsymbol{m}_{\boldsymbol{x v s}} \\
{[\mathbf{k N m}]}\end{array}$ & $\begin{array}{c}\boldsymbol{m}_{\mathbf{y}} \boldsymbol{s} \\
{[\mathbf{k N m}]}\end{array}$ & $\begin{array}{c}\boldsymbol{w}_{\boldsymbol{s}} \\
{[\mathbf{m m}]}\end{array}$ & $\begin{array}{c}\boldsymbol{\Psi} \\
{[\mathbf{d e g}]}\end{array}$ & $\begin{array}{c}\boldsymbol{\Psi}^{*} \\
{[\%]}\end{array}$ \\
\hline 8.46 & 0.065 & 31.56 & 0.966 & 1.06 & 0.76 & -2.48 & -2.19 & 28.82 & 3.00 & 100 \\
\hline 26.91 & 0.1 & 31.56 & 1.107 & 3.86 & 2.79 & -9.05 & -7.97 & 28.85 & 3.00 & 100 \\
\hline 84.11 & 0.15 & 31.56 & 1.196 & 13.01 & 9.40 & -30.53 & -26.91 & 28.85 & 3.00 & 100 \\
\hline 632.94 & 0.3 & 31.56 & 1.271 & 104.11 & 75.23 & -244.29 & -215.29 & 28.85 & 3.00 & 100 \\
\hline
\end{tabular}

As can be seen in Table 4, a breakthrough of $65 \mathrm{~mm}$ thick masonry wall would occur at a pressure of $8.46 \mathrm{kPa}$ at the initial intact wall structure. The resulting values roughly correspond to expert estimates and experimental measurements that were made to study the different types of materials.

\section{Conclusion}

Comparing the results of analytical calculations and experimental measurements, we conclude that the results are only partially consistent for several reasons:

- we calculated with average values based on experts estimates

- it is not possible to take into account all factors affecting the consequences of an explosion in a real environment,

- experimental pressure testing was carried out on one wall many times in succession,

- cracks and wall weakening occurred during individual tests which could not be included in the analytical calculations,

- to estimate of the value of the ductility coefficient (it is not possible to determine the exact value).

In conclusion, it should be noted that the explosion does not only produce the effects of pressure. A great role is also played by the temperature, which is released and thus disrupts the structure of the individual materials. After considering the all effects of the explosion that it is possible to create an effective way of protecting the individual elements of the critical infrastructure and private buildings [20,21].

The work was supported by the Internal Grant Scheme of Faculty of Security Engineering, University of Zilina from the grant No. 2019/10. 


\section{References}

1. T. Loveček, A. Velas, K. Kampová, L. Mariš, V. Mózer, International Carnahan Conference of Security Technology (2013)

2. L. Figuli, V. Kavický, Š. Jangl, Z. Zvaková, Communications: scientific letters of the University of Žilina, 20, 2 (2018)

3. D. Papán, Z. Papánová, MATEC Web of Conferences 196, 01037 (2018)

4. D. Papán, Z. Papánová, MATEC Web of Conferences 251, 04057 (2018)

5. D. Papán, Z. Papánová, Procedia Eng. 91 (2014).

6. L. Figuli, et al, IOP Conf. Ser. Earth Environ. Sci. 44 (2016)

7. L. Figuli, Z. Zvaková, C. Bedon, Procedia Eng. 192 (2017)

8. L. Figuli, C. Bedon, Z. Zvaková, Š. Jangl, V. Kavický, Procedia Eng. 199 (2017)

9. J. Fládr et al, IOP Conf. Ser.: Mater. Sci. Eng. 596 (2019)

10. T. Trtík et al, IOP Conf. Ser.: Mater. Sci. Eng. 596 (2019)

11. L. Figuli, S. Lichorobiec, Communications: scientific letters of the University of Žilina, 20, 2 (2018)

12. L. Figuli, D. Papan, Applied Mechanics and Materials, 617 (2014)

13. J. Henrych, The Dynamics of Explosion and Its Use (Elsevier, 1979)

14. V. Kavicky, L. Figuli, S. Jangl, Z. Ligasová, WIT Transactions on The Built Environment, 141 (WIT Press 2014)

15. D. Makovicka, B. Janovsky, Prirucka proti vybuchovej ochrany staveb (CVUT, 2008, in Czech)

16. J. Hořejší, J. Šafka, J., Statické tabulky, TP 51, (SNTL, 1987, in Slovak)

17. D. Makovicka, WIT Transactions on The Built Environment, 63 (WIT Press, 2002)

18. D. Makovička, CTU Reports, Theoretical and Experimental Research in Structural Engineering, 4 (CTU Publishing House, 2000)

19. D. Makovička, Vliv opakovaných extrémních zatížení na ohybovou únosnost zdiva, (ČVUT, 2006, in Czech)

20. V. Mozer, A. Osvald, T. Lovecek, A. Fanfarova, L. Vrablova, International Carnahan Conference of Security Technology (2013)

21. T. Lovecek, Communications: scientific letters of the University of Žilina, 10, 2, 35-39 (2008) 